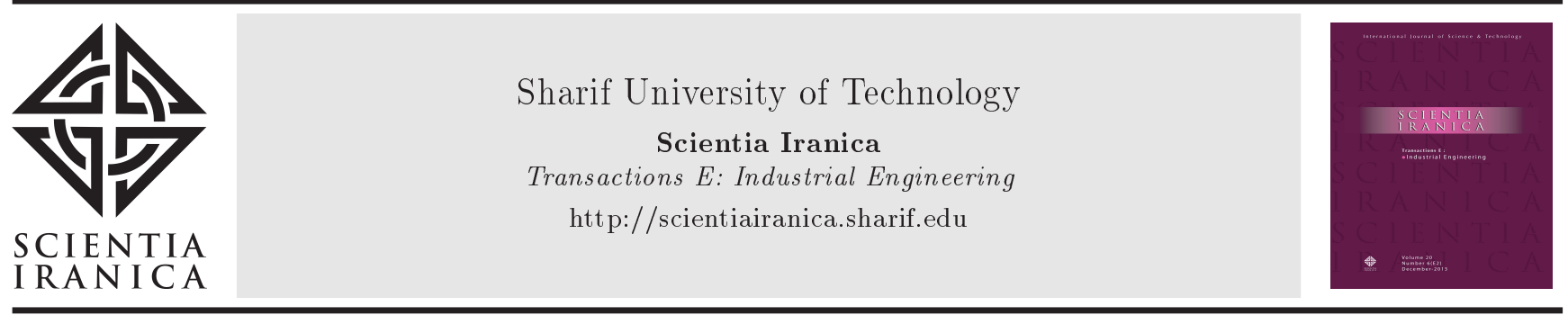

\title{
Weight determination and ranking priority in interval group MCDM
}

\author{
S. Saffarzadeh, A. Hadi-Vencheh*, and A. Jamshidi \\ Department of Mathematics, Isfahan (Khorasgan) Branch, Islamic Azad University, Isfahan, Iran.
}

Received 29 May 2018; received in revised form 1 March 2019; accepted 4 May 2019

\section{KEYWORDS}

Decision analysis;

GMCDM;

TOPSIS;

Interval matrix;

Weight of criteria.

\begin{abstract}
This study proposes a method for determining the weight of Decision Makers (DMs) in Group Multiple Criteria Decision Making (GMCDM) problems with interval data. Here, an interval weight of each DM was obtained; then, the relative closeness of each decision to Negative Ideal Solution (NIS) and Positive Ideal Solution (PIS) was then computed. By using the proposed method, after weighting the decision matrix of each DM, the alternatives were ranked using interval arithmetic. A comparative example along with a real-world problem concerning the air quality assessment was given to illustrate the viability of the proposed method.
\end{abstract}

2020 Sharif University of Technology. All rights reserved.

\section{Introduction}

Multiple Criteria Decision Making (MCDM) problems are an important field of study in management, decision science, and operations research [1]. This field has attracted the attention of many researchers over the last decade and many approaches have been presented so far to solve the MCDM problems [2]. In MCDM problems, the aggregated performance of alternatives is measured based on a set of criteria. Based on this assessment, the alternatives are ranked first and then, those with the best aggregate performance are selected for implementation [3-8].

The methods employed to assess the aggregate performance of alternatives are different in terms of the aggregate functions. For instance, the simple additive weighting method [9] incorporates a simple aggregate

\footnotetext{
* Corresponding author. Tel.: +983135354001

Fax: +983135354060;

E-mail addresses: s.saffarzadeh@gmail.com (S.

Saffarzadeh); ahadi@khuisf.ac.ir (A. Hadi-Vencheh);

ali.jamshidi@khuisf.ac.ir (A. Jamshidi)
}

doi: $10.24200 /$ sci.2019.51133.2022 function, Technique for Order Preference by Similarity to Ideal Solution (TOPSIS) [9], and Vlse Kriterijumska Optimizacija I Kompromisno Resenje (VIKOR) [10] and an alternative or a compromise solution that can be close to Positive Ideal Solution (PIS) as much as possible and as far away from the Negative Ideal Solution (NIS) as possible is sought. The Analytical Hierarchy Process (AHP) [11] in which DM provides pairwise comparison judgments on a ratio scale of 1 to 9 . The Simple Multi-Attribute Rating Technique (SMART) method [12] is aimed at gathering direct ratings on a scale of 0 to 100, and the Measuring Attractiveness by a Categorical Based Evaluation Technique (MACBETH) method [13] requires pairwise comparisons on an interval. The other method is ELimination Et Choix Traduisant la REalité (ELECTRE), which is presented in different types. It is worth mentioning that the study of Govindan and Jespen [14] is a comprehensive source of ELECTRE and ELECTRE-based methods. Their study considered different types of ELECTRE methods and compared, modified, and defined the area of applications of each method. Recently, Ishizaka and Siraj [15] applied AHP, SMART, and MAGBETH to a real MCDM problem. The authors investigated 
whether these three methods would really help the DMs or not. The assessment of public transport satisfaction was conducted by Nassereddine and Eskandari [16]. For this purpose, the authors employed an integrated MCDM technique. Their method is a combination of Delphi, Group AHP (GAHP), and Preference Ranking Organization METHod for Enrichment of Evaluations (PROMETHEE). A method based on TOPSIS and entropy was proposed by Abdollahi et al. [17] to rank multifarious Demand Response Resources (DRRs). It is noted that the MCDM models are widely applied to systems engineering [18-22].

Indeed, most of the above-mentioned methods include one DM, while real-life problems have different managerial, engineering, social, and other aspects involving a group of DMs. Studies such as [23-29] used methods to solve Group Multiple Criteria Decision Making (GMCDM) problems. These methods were applied to the cases in which data were exact and had crisp values. However, in most real-world problems, decision information is expressed as an interval or fuzzy number [30].

Nowadays, Fuzzy MCDM (FMCDM) problems play an important role in industrial and system engineering. An extension of fuzzy VIKOR to solving supplier selection problem was presented by Mahmoudi et al. [31]. In the case of this method, a fuzzy distance measure was proposed to rank the suppliers. Besides, unequal weights of DMs and the performance of each supplier under each criterion were represented by a linguistic variable. Finally, the alternatives were ranked by the preference ratio method. An MCDM problem with stochastic and intuitionistic data was proposed by $\mathrm{Hu}$ et al. [32]. The problem of dam site selection was considered as a Group FMCDM (GFMCDM) by Minatour et al. [33]. To solve the problem, the authors integrated Fuzzy AHP (FAHP) with VIKOR. More recently, Yu et al. [34] provided new indices to solve MCDM problems. More specifically, they considered the MCDM problems with ranked criteria. They proposed a solving method based on digraphs and fuzzy measures.

Although the focus on interval numbers has been lower than fuzzy numbers in uncertain MCDM problems, useful pieces of researches have been carried out in this case [35-43]. Yue [35] developed the TOPSIS method to solve interval GMCDM problems. In the mentioned paper, two consecutive normalization steps were taken to normalize the decision matrices, which could be time consuming in large problems. Moreover, the relative closeness of each individual decision from PIS and NIS was obtained as a real number; therefore, the weight of each DM is an exact number which is not compatible with the interval nature of the problem. Besides, transformation of interval numbers to exact ones leads to loss of some information. Jahanshahloo et al. [36] developed the TOPSIS method for solving MCDM problems with interval numbers. In their research, first, the PIS and NIS were determined by a particular algorithm and then, the distance of each alternative from the PIS and the NIS was obtained by interval arithmetic. Sayadi et al. [37] extended the VIKOR method in the presence of interval numbers. In their method, first, the PIS and NIS were determined; then, utility and regret measures and VIKOR index were obtained for each alternative; finally, VIKOR indexes including interval numbers were compared together. For this purpose, a coefficient called the optimism level of DM was introduced, by which interval numbers were compared and the alternatives were ranked. Dymova et al. [39] developed interval TOPSIS method, which is fundamentally different from similar methods. The first difference is that the interval numbers are compared; then, the PIS and NIS are determined. The second difference is that the separation measures of each alternative from the NIS and PIS are taken by calculating the separation of centers of intervals. Using this measure does not require Euclidean or Hamming distance to compute the distance of each alternative from the PIS and NIS. Rezaei and Salimi [38] provided a method for $\mathrm{ABC}$ inventory classification with interval numbers. They employed this method to solve an interval programming problem with the objective function of minimizing total costs (control and nocontrol costs). Hafezalkotob et al. [40] developed interval Multiplicative Multi-Objective Optimization based on Ratio Analysis (MULTIMOORA) method. In their study, the decision matrices were normalized and weighted. Then, to rank the alternatives, the interval numbers were compared by their degree of possibility. Liu and $\mathrm{Li}$ [41] considered interval MAGDM problems. Their method first considers an exogenous weight of each DM. Next, the weight of each DM was obtained by adjusting these exogenous weights and using Plant Growth Simulation Algorithm (PGSA). It is noted that their method ranks the DMs and does not rank the alternatives. Moreover, the weight of each DM is strongly influenced by the primary exogenous weights and as a result, the final ranking is not unique because these primary weights are subjective. Wanke et al. [44] proposed an integrated FMCDM neural-network approach to predicting the performance of ASEAN banks. A hybrid MCDM model including Interval Rough AHP (IRAHP) and Multi-Attributive Border Approximation Area Comparison (MABAC) were proposed by Pamučar et al. [42]. The model was then employed to solve the GMCDM problem and the weight of criteria was determined by IRAHP approach. Feng et al. [43] combined DEMATEL, analytical network process, and interval VIKOR to solve the product optimization problem. Hajek and Froelich [45] proposed 
integrating TOPSIS with interval-valued intuitionistic fuzzy cognitive maps for effective group decision making. Frini and Amor [46] proposed a temporal outranking method, named MUPOM (MUlti-criteria multi-Period Outranking Method), which accommodates the requirements of sustainable development and demonstrates how the paradigm behind outranking methods can be of use in processing temporal impacts of decisions. The proposed method is structured in four phases: multi-criteria aggregation, temporal aggregation, exploitation, and follow-up.

As mentioned, sometimes, information of decision-makers or the performance of each alternative under each criterion is not available as a crisp number and we just know the range of these values. This means that the values are available as interval numbers. Compared to FMCDM papers, there are fewer papers on interval MCGDM problems. Further, the whole computations are not completely based on interval arithmetic in most interval MCGDMs. For instance, to calculate the distance of each decision from PIS and NIS, calculations are done as crisp numbers rather than interval numbers [35]. The current paper makes five major contributions. First, the proposed approach incorporates the interval data into the MCDM problems and all calculations are done in the interval form. Second, given that the primary information is interval based and since the endogenous weights are obtained from the primary data, the weights are obtained as the interval; in addition, this is more consistent with the interval nature of the problem and appears more logical. Third, the opinion of each DM on the performance of alternatives under criteria is expressed by an interval matrix and the PIS and NIS are obtained as interval matrices. Fourth, the ranking order of DMs is obtained using the relative closeness of each individual decision matrix to the NIS and the PIS; then, the weight of each DM is obtained as an interval number. Ultimately, all the alternatives are ranked after weighting the decision matrices.

In the following section, some preliminaries concerning interval numbers and their arithmetic are given. Section 3 is devoted to the proposed method and its algorithm. A numerical example taken from literature is given to compare our method and those published in literature in Section 4. To demonstrate relevancy of our method, a real case related to the assessment of air pollution is provided in this section, too. Conclusions are given in Section 5 .

\section{Interval definitions and arithmetic}

Now, some interval definitions and arithmetic are given. These preliminaries will be used in the next sections [47-49].
Definition 1. Interval number $a$ is shown as $a=$ $\left[a^{l}, a^{u}\right]$, where $a^{l}$ and $a^{u}$ are real numbers and represent the lower and upper bounds of $a$, respectively, and $a^{l} \leq a^{u}$.

If $a^{l}>0$, then we say $a$ is positive; if $a^{l} \geq 0$, then $a$ is called non-negative. If $a^{l}=a^{u}$, then $a$ is a real number. We show the set of all interval numbers in $\mathbb{R}$ by $I(\mathbb{R}) I(\mathbb{R})$. Let $a=\left[a^{l}, a^{u}\right]$ and $b=\left[b^{l}, b^{u}\right]$ be two interval numbers, $\lambda$ be a real number, and $\lambda \geq 0$. Then, we get:

$$
\begin{aligned}
& a+b=\left[a^{l}+b^{l}, a^{u}+b^{u}\right], \\
& a-b=\left[a^{l}-b^{u}, a^{u}-b^{l}\right], \\
& \lambda a=\left[\lambda a^{l}, \lambda a^{u}\right], \\
& a * b=\left[\min \left\{a^{l} b^{l}, a^{l} b^{u}, a^{u} b^{l}, a^{u} b^{u}\right\},\right. \\
& \left.\max \left\{a^{l} b^{l}, a^{l} b^{u}, a^{u} b^{l}, a^{u} b^{u}\right\}\right], \\
& a^{2}=\left[\max \left\{0, \min \left\{a^{l} a^{l}, a^{l} a^{u}, a^{u} a^{u}\right\}\right\},\right. \\
& \left.\max \left\{a^{l} a^{l}, a^{l} a^{u}, a^{u} a^{u}\right\}\right], \\
& \text { If } a^{l} \geq 0 \text {, then } \sqrt{a}=\left[\sqrt{a^{l}}, \sqrt{a^{u}}\right] \text {. }
\end{aligned}
$$

Definition 2. Assume that $a=\left[a^{l}, a^{u}\right]$ and $b=$ $\left[b^{l}, b^{u}\right]$ are two non-negative interval numbers; then, we define the degree of possibility of $a \geq b$ as follows:

$$
p(a \geq b)=\max \left\{1-\max \left(\frac{b^{u}-a^{l}}{l_{a}+l_{b}}, 0\right), 0\right\},
$$

where $l_{a}=a^{u}-a^{l}, l_{b}=b^{u}-b^{l}$ satisfying the following properties:

a. $0 \leq p(a \geq b) \leq 1$,

b. $p(a \geq b)=0$ if and only if $a^{u} \leq b^{l}$,

c. $p(a \geq b)=1$ if and only if $b^{u} \leq a^{l}$,

d. $p(a \geq a)=\frac{1}{2}$

e. $p(a \geq b)+p(b \geq a)=1$.

For comparing and ranking the non-negative interval numbers $a_{i}=\left[a_{i}^{l}, a_{i}^{u}\right](i=1,2, \ldots, n)$ in descending order, the following steps are utilized:

(1) Compare the interval numbers $a_{i}(i=1,2, \ldots, n)$ pairwise by Eq. (1) and let: $p_{i j}=p\left(a_{i} \geq a_{j}\right)$ $i, j=1,2, \ldots, n$.

(2) Construct a matrix called the complementary matrix as follows:

$$
P=\left(p_{i j}\right)_{n \times n} \text {. }
$$

(3) Sum up all components of each row of matrix $P$ together and let: 


$$
p_{i}=\sum_{j=1}^{n} p_{i j}, \quad i=1,2, \ldots, n .
$$

(4) Rank the interval numbers $a_{i}(i=1,2, \ldots, n)$ in the descending order using $p_{i}$ values.

\section{The proposed method}

This section presents our method. Here, the opinion of each DM on the performance of each alternative under criteria is expressed by a non-negative interval matrix. Let $D=\left\{d_{1}, d_{2}, \ldots, d_{t}\right\}$ be a group of DMs and $\lambda_{k}=\left[\lambda_{k}^{l}, \lambda_{k}^{u}\right]$ shows the weight of the $k$ th $(k=1,2, \ldots, t) \mathrm{DM}, A=\left\{A_{1}, A_{2}, \ldots, A_{m}\right\}(m \geq 2)$ be a set of alternatives, and $C=\left\{c_{1}, c_{2}, \ldots, c_{n}\right\}$ be a set of criteria. Let $w_{j}$ be the weight of the $j$ th criterion and $\sum_{j=1}^{n} w_{j}=1, w_{j} \geq 0, j=1,2, \ldots, n$. We show the decision matrix of the $k$ th DM by interval matrix, $X_{k}=\left(x_{i j}^{k}\right)_{m \times n}, k=1,2, \ldots, t ; i=1,2, \ldots, m ; j=$ $1,2, \ldots, n$, where $x_{i j}^{k}=\left[x_{i j}^{k(l)}, x_{i j}^{k(u)}\right]$ is a non-negative interval number and $x_{i j}^{k}$ shows the opinion of the $k$ th DM on the performance of the $i$ th alternative under the $j$ th criterion. Thus, we get:

$$
\begin{aligned}
& X_{k}=\left(\left[x_{i j}^{k(l)}, x_{i j}^{k(u)}\right]\right)_{m \times n}= \\
& {\left[\begin{array}{cccc}
{\left[x_{11}^{k(l)}, x_{11}^{k(u)}\right]} & {\left[x_{12}^{k(l)}, x_{12}^{k(u)}\right]} & \ldots & {\left[x_{1 n}^{k(l)}, x_{1 n}^{k(u)}\right]} \\
{\left[x_{21}^{k(l)}, x_{21}^{k(u)}\right]} & {\left[x_{22}^{k(l)}, x_{22}^{k(u)}\right]} & \ldots & {\left[x_{2 n}^{k(l)}, x_{2 n}^{k(u)}\right]} \\
\vdots & \vdots & \vdots & \vdots \\
{\left[x_{m 1}^{k(l)}, x_{m 1}^{k(u)}\right]} & {\left[x_{m 2}^{k(l)}, x_{m 2}^{k(u)}\right]} & \ldots & {\left[x_{m n}^{k(l)}, x_{m n}^{k(u)}\right]}
\end{array}\right]} \\
& k=1,2, \ldots, t .
\end{aligned}
$$

First, to normalize the decision matrix, we define:

$$
\begin{aligned}
R_{k} & =\left(\left[r_{i j}^{k(l)}, r_{i j}^{k(u)}\right]\right)_{m \times n} \\
k & =1,2, \ldots, t ; \quad i=1,2, \ldots, m ; \quad j=1,2, \ldots, n,
\end{aligned}
$$

where:

For benefit criteria:

$$
\begin{aligned}
& {\left[r_{i j}^{k(l)}, r_{i j}^{k(u)}\right]} \\
& \quad=\left[\frac{x_{i j}^{k(l)}}{\max _{i=1,2, \ldots, m}\left(x_{i j}^{k(u)}\right)}, \frac{x_{i j}^{k(u)}}{\max _{i=1,2, \ldots, m}\left(x_{i j}^{k(u)}\right)}\right] .
\end{aligned}
$$

For cost criteria:

$$
\begin{aligned}
& {\left[r_{i j}^{k(l)}, r_{i j}^{k(u)}\right]} \\
& \quad=\left[\frac{\min _{i=1,2, \ldots, m}\left(x_{i j}^{k(l)}\right)}{x_{i j}^{k(u)}}, \frac{\min _{i=1,2, \ldots, m}\left(x_{i j}^{k(l)}\right)}{x_{i j}^{k(l)}}\right]
\end{aligned}
$$

Clearly, $\left[r_{i j}^{k(l)}, r_{i j}^{k(u)}\right]$ is a non-negative interval number and $r_{i j}^{k(u)} \leq 1$.

Further, the weighted decision matrices are obtained as follows:

$$
\begin{aligned}
& V_{k}=\left(\left[v_{i j}^{k(l)}, v_{i j}^{k(u)}\right]\right)_{m \times n}=\left(\left[w_{j} r_{i j}^{k(l)}, w_{j} r_{i j}^{k(u)}\right]\right)_{m \times n} \\
& k=1,2, \ldots, t ; \quad i=1,2, \ldots, m ; \quad j=1,2, \ldots, n .
\end{aligned}
$$

Then, the average of weighted matrices is considered as the PIS. Thus:

$$
A^{+}=\left(\left[v_{i j}^{+(l)}, v_{i j}^{+(u)}\right]\right)_{m \times n}
$$

where $v_{i j}^{+(l)}=\frac{1}{t} \sum_{k=1}^{t} v_{i j}^{k(l)}$ and $v_{i j}^{+(u)}=\frac{1}{t} \sum_{k=1}^{t} v_{i j}^{k(u)}$. Next, the NIS is defined as follows:

$$
A^{-}=\left(\left[v_{i j}^{-(l)}, v_{i j}^{-(u)}\right]\right)_{m \times n},
$$

in which:

$$
v_{i j}^{-(l)}=\min _{k=1,2, \ldots, t}\left\{v_{i j}^{k(l)}\right\}
$$

and:

$$
v_{i j}^{-(u)}=\max _{k=1,2, \ldots, t}\left\{v_{i j}^{k(u)}\right\} .
$$

The separation measures of the decision matrix of the $k$ th DM from the PIS and NIS, which are interval numbers, are respectively calculated using the following formulas:

$$
\begin{aligned}
s_{k}^{+} & =\left[s_{k}^{+(l)}, s_{k}^{+(u)}\right] \\
& =\sqrt{\sum_{i=1}^{m} \sum_{j=1}^{n}\left[v_{i j}^{k(l)}-v_{i j}^{+(u)}, v_{i j}^{k(u)}-v_{i j}^{+(l)}\right]^{2}} \\
k & =1,2, \ldots, t,
\end{aligned}
$$

and,

$$
\begin{aligned}
s_{k}^{-} & =\left[s_{k}^{-(l)}, s_{k}^{-(u)}\right] \\
& =\sqrt{\sum_{i=1}^{m} \sum_{j=1}^{n}\left[v_{i j}^{k(l)}-v_{i j}^{-(u)}, v_{i j}^{k(u)}-v_{i j}^{-(l)}\right]^{2}} \\
k & =1,2, \ldots, t .
\end{aligned}
$$


Since all components of $A^{+}$and $A^{-}$belong to $[0,1], s_{k}^{+}$ and $s_{k}^{-}$belong to $[0,1]$, too. A decision matrix that is farther away from the NIS and the closer to the PIS is preferred. However, the decision matrix which is closer to the PIS is not essentially the same as that being farther away from the NIS [50]. Thus, we should calculate the relative closeness of each decision matrix with respect to the PIS. Since the main idea of the proposed method is taken from TOPSIS, the relative closeness of the $k$ th decision matrix with respect to the PIS, which is an interval number, is calculated as follows:

$$
R C_{k}=\left[R C_{k}^{l}, R C_{k}^{u}\right] \quad k=1,2, \ldots, t,
$$

where:

$$
R C_{k}^{l}=\frac{s_{k}^{-(l)}+2}{s_{k}^{-(u)}+s_{k}^{+(u)}+4}, \quad R C_{k}^{u}=\frac{s_{k}^{-(u)}+2}{s_{k}^{-(l)}+s_{k}^{+(l)}+4} .
$$

Clearly, $R C_{k} \in(0,1]$.

Remark 1. In the above formulas, two units are added to the interval numbers $s_{k}^{+}$and $s_{k}^{-}$to prevent the dominator from being zero.

Now, the interval weight of the $k$ th $(k=1,2$, $\ldots, t) \mathrm{DM}$ is defined as follows:

$$
\lambda_{k}=\left[\lambda_{k}^{l}, \lambda_{k}^{u}\right], \quad k=1,2, \ldots, t,
$$

where:

$$
\lambda_{k}^{l}=\frac{R C_{k}^{l}}{\sum_{k=1}^{t} R C_{k}^{u}} \quad \text { and } \quad \lambda_{k}^{u}=\frac{R C_{k}^{u}}{\sum_{k=1}^{t} R C_{k}^{l}} .
$$

Thus, the weight of each DM is obtained as an interval number, which is more reasonable. Nevertheless, if one needs to rank the DMs, the complementary matrix $P$ is used to rank all DMs in descending order by employing $R C_{k}$ values. For this purpose, each decision matrix is weighted as follows:

$$
\begin{aligned}
V_{k} & =\left(\left[\lambda_{k}^{l} v_{i j}^{k(l)}, \lambda_{k}^{u} v_{i j}^{k(u)}\right]\right)_{m \times n} \\
k & =1,2, \ldots, t ; \quad i=1,2, \ldots, m ; \quad j=1,2, \ldots, n .
\end{aligned}
$$

Then, the collective matrix $V$ is constructed by:

$$
\begin{aligned}
& V=\sum_{k=1}^{t} V_{k}=\left(\left[v_{i j}^{l}, v_{i j}^{u}\right]\right)_{m \times n} \\
& i=1,2, \ldots, m ; j=1,2, \ldots, n .
\end{aligned}
$$

Given that each row of matrix $V$ corresponds to an alternative, these rows should be compared with each other. For this purpose, we define:

$$
V_{i}=\left[v_{i}^{l}, v_{i}^{u}\right], \quad i=1,2, \ldots, m,
$$

where:

$$
v_{i}^{l}=\sum_{j=1}^{n} v_{i j}^{l} \quad \text { and } \quad v_{i}^{u}=\sum_{j=1}^{n} v_{i j}^{u} .
$$

Now, as mentioned in Section 2, the interval numbers $V_{i}$ are compared. Therefore, the complimentary matrix $P$ is derived using Eq. (1) as follows:

$$
P=\left(p_{i j}\right)_{m \times m} \quad i, j=1,2, \ldots, m,
$$

where,

$$
p_{i j}=p\left(V_{i} \geq V_{j}\right) .
$$

Then, summing up all elements in each row of matrix $P$ yields:

$$
p_{i}=\sum_{j=1}^{m} p_{i j} \quad i=1,2, \ldots, m .
$$

Ultimately, all alternatives are ranked based on $p_{i}(i=1,2, \ldots, m)$ values in the descending order.

Remark 2. Let $w_{k}$ be the exogenous weight of the $k$ th DM; then, the value of $\lambda_{k}$ is modified as follows:

$$
\lambda_{k}=\left[\lambda_{k}^{l}, \lambda_{k}^{u}\right] \quad k=1,2, \ldots, t,
$$

where,

$$
\lambda_{k}^{l}=\frac{R C_{k}^{l} w_{k}}{\sum_{k=1}^{t} R C_{k}^{u} w_{k}} \quad \text { and } \quad \lambda_{k}^{u}=\frac{R C_{k}^{u} w_{k}}{\sum_{k=1}^{t} R C_{k}^{l} w_{k}} .
$$

Briefly, the algorithm of the proposed method is summarized by the following steps:

Step 1. Convert interval matrix $X_{k}(k=1,2, \ldots, t)$ (decision matrix of the $k$ th $\mathrm{DM}$ ) to interval matrix $R_{k}$ by Eqs. (5)-(7);

Step 2. Compute weighted interval matrix $V_{k}$ by Eq. (8);

Step 3. Employ Eqs. (9) and (10) to compute the PIS and NIS, respectively;

Step 4. Compute the separation measures of decision matrix of the $k$ th $(k=1,2, \ldots, t)$ DM from the PIS and NIS by Eqs. (11) and (12), respectively;

Step 5. Obtain the relative closeness of decision matrix of the $k$ th $(k=1,2, \ldots, t) \mathrm{DM}$ with respect to the PIS by Eq. (13) and rank all DMs in descending order by $R C_{k}$ values;

Step 6. Apply Eq. (14) to determine the weight of the $k$ th $(k=1,2, \ldots, t) \mathrm{DM}$; 
Step 7. Weigh the decision matrices using Eq. (15);

Step 8. Utilize Eq. (16) to construct collective matrix $V$;

Step 9. Calculate interval numbers $V_{i}(i=1,2, \ldots$, m) using Eq. (17);

Step 10. Employ Eq. (18) and construct the complimentary matrix to compare interval numbers $V_{i}(i=1,2, \ldots, m)$;

Step 11. Calculate $P_{i}(i=1,2, \ldots, m)$ values using Eq. (19) and rank the alternatives.

\section{Illustrative examples}

In this section, a comparative example along with a real case is given to clarify the proposed method.

Example 1. We reconsider the example presented in Liu and $\mathrm{Li}$ [41] with six alternatives, four criteria, and four DMs. The judgment information of four DMs is shown in Tables 1-4.

Liu and $\mathrm{Li}$ (2015) first considered an exogenous weight of each DM. Based on findings of Liu and Li [41], the subjective weights are $w_{1}=0.3, w_{2}=0.4, w_{3}=$ 0.1 , and $w_{4}=0.2$. Then, the weight of each DM is obtained by adjusting these exogenous weights and using PGSA. Their method ranks the DMs and does not rank the alternatives. Now, the proposed method is applied assuming the same importance of all DMs. After taking the steps of the proposed method and

Table 1. Decision matrix, $X_{1}$, for Example 1.

\begin{tabular}{ccccc}
\hline Alternative & $\boldsymbol{c}_{\boldsymbol{1}}$ & $\boldsymbol{c}_{\boldsymbol{2}}$ & $\boldsymbol{c}_{\boldsymbol{3}}$ & $\boldsymbol{c}_{\boldsymbol{4}}$ \\
\hline$A_{1}$ & {$[1.8,2.2]$} & {$[1.2,1.8]$} & {$[1.8,2.3]$} & {$[5.4,5.6]$} \\
$A_{2}$ & {$[2.5,2.7]$} & {$[2.8,3.0]$} & {$[1.8,2.0]$} & {$[6.5,6.6]$} \\
$A_{3}$ & {$[1.8,2.3]$} & {$[1.6,2.0]$} & {$[1.9,2.3]$} & {$[4.4,4.6]$} \\
$A_{4}$ & {$[2.0,2.4]$} & {$[1.5,2.1]$} & {$[1.8,2.3]$} & {$[4.9,5.1]$} \\
$A_{5}$ & {$[1.2,1.8]$} & {$[1.7,2.5]$} & {$[1.7,2.3]$} & {$[5.3,5.7]$} \\
$A_{6}$ & {$[2.3,2.6]$} & {$[2.3,2.9]$} & {$[1.6,2.2]$} & {$[5.9,6.3]$} \\
\hline
\end{tabular}

Table 2. Decision matrix, $X_{2}$, for Example 1.

\begin{tabular}{ccccc}
\hline Alternative & $\boldsymbol{c}_{\boldsymbol{1}}$ & $\boldsymbol{c}_{\boldsymbol{2}}$ & $\boldsymbol{c}_{\boldsymbol{3}}$ & $\boldsymbol{c}_{\boldsymbol{4}}$ \\
\hline$A_{1}$ & {$[1.6,2.0]$} & {$[1.3,1.9]$} & {$[1.9,2.4]$} & {$[5.3,5.8]$} \\
$A_{2}$ & {$[2.2,2.6]$} & {$[2.9,3.1]$} & {$[1.9,2.1]$} & {$[6.7,6.8]$} \\
$A_{3}$ & {$[1.5,2.1]$} & {$[1.9,2.4]$} & {$[2.0,2.4]$} & {$[4.6,4.8]$} \\
$A_{4}$ & {$[2.0,2.4]$} & {$[1.6,2.2]$} & {$[1.9,2.5]$} & {$[5.1,5.3]$} \\
$A_{5}$ & {$[2.1,2.3]$} & {$[1.8,2.7]$} & {$[1.8,2.3]$} & {$[4.3,4.9]$} \\
$A_{6}$ & {$[3.1,3.3]$} & {$[2.1,3.4]$} & {$[2.1,2.4]$} & {$[5.5,5.8]$} \\
\hline
\end{tabular}

Table 3. Decision matrix, $X_{3}$, for Example 1.

\begin{tabular}{ccccc}
\hline Alternative & $\boldsymbol{c}_{\mathbf{1}}$ & $\boldsymbol{c}_{\boldsymbol{2}}$ & $\boldsymbol{c}_{\boldsymbol{3}}$ & $\boldsymbol{c}_{\boldsymbol{4}}$ \\
\hline$A_{1}$ & {$[1.0,1.0]$} & {$[1.0,1.5]$} & {$[1.3,2.0]$} & {$[4.8,5.2]$} \\
$A_{2}$ & {$[1.6,1.6]$} & {$[2.4,2.5]$} & {$[1.3,1.7]$} & {$[6.0,6.1]$} \\
$A_{3}$ & {$[1.1,1.5]$} & {$[1.3,2.0]$} & {$[1.5,1.8]$} & {$[4.1,4.2]$} \\
$A_{4}$ & {$[1.6,2.0]$} & {$[1.1,1.7]$} & {$[1.3,2.0]$} & {$[4.6,4.9]$} \\
$A_{5}$ & {$[1.7,2.3]$} & {$[1.3,1.8]$} & {$[1.6,2.1]$} & {$[5.4,5.8]$} \\
$A_{6}$ & {$[2.1,2.8]$} & {$[2.2,3.2]$} & {$[1.7,2.4]$} & {$[4.6,6.1]$} \\
\hline
\end{tabular}

Table 4. Decision matrix, $X_{4}$, for Example 1.

\begin{tabular}{ccccc}
\hline Alternative & $\boldsymbol{c}_{\boldsymbol{1}}$ & $\boldsymbol{c}_{\boldsymbol{2}}$ & $\boldsymbol{c}_{\boldsymbol{3}}$ & $\boldsymbol{c}_{\boldsymbol{4}}$ \\
\hline$A_{1}$ & {$[1.6,2.0]$} & {$[1.3,1.9]$} & {$[1.9,2.4]$} & {$[5.3,5.8]$} \\
$A_{2}$ & {$[2.2,2.6]$} & {$[2.9,3.1]$} & {$[1.9,2.1]$} & {$[6.7,6.8]$} \\
$A_{3}$ & {$[1.5,2.1]$} & {$[1.9,2.4]$} & {$[2.0,2.4]$} & {$[4.6,4.8]$} \\
$A_{4}$ & {$[2.0,2.4]$} & {$[1.6,2.2]$} & {$[1.9,2.5]$} & {$[5.1,5.3]$} \\
$A_{5}$ & {$[1.8,2.7]$} & {$[2.1,2.7]$} & {$[1.7,2.2]$} & {$[4.8,5.3]$} \\
$A_{6}$ & {$[2.5,2.9]$} & {$[1.4,3.1]$} & {$[1.8,2.4]$} & {$[5.1,6.2]$} \\
\hline
\end{tabular}

Table 5. Comparison of the present method with Liu and Li method.

\begin{tabular}{cccccc}
\hline \multirow{2}{*}{ DM } & \multicolumn{2}{c}{ Proposed method } & & \multicolumn{2}{c}{ Liu and Li method } \\
\cline { 2 - 3 } \cline { 5 - 6 } & Weight & Ranking & & Weight & Ranking \\
\hline$d_{1}$ & {$[0.21436,0.41871]$} & 2 & & 0.2762 & 2 \\
$d_{2}$ & {$[0.29175,0.55131]$} & 1 & & 0.3677 & 1 \\
$d_{3}$ & {$[0.07074,0.13911]$} & 4 & & 0.0948 & 4 \\
$d_{4}$ & {$[0.14348,0.27911]$} & 3 & & 0.2613 & 3 \\
\hline
\end{tabular}

obtaining $R C_{k}=\left[R C_{k}^{l}, R C_{k}^{u}\right] ; k=1,2,3,4$, we insert the primary exogenous weights $\left(w_{1}=0.3, w_{2}=\right.$ $0.4, w_{3}=0.1, w_{4}=0.2$ ), by Eq. (20). As seen in Table 5, the ranking of DMs using both methods is the same; however, as mentioned, primary exogenous weights are very influential in the method of Liu and $\mathrm{Li}$ and it is necessary to determine those at the beginning of the procedure. It is noteworthy that the proposed method is not dependent on choosing the primary weights.

Example 2. Air pollution, due to its harmful consequences, has become one of the most tangible and perilous environmental problems. In Iran, 45,000 people die annually due to air pollution. Tehran is the largest city and capital of Iran with a population of about 8 million and an area of about $730 \mathrm{~km}^{2}$. Tehran is one of the most polluted cities in the world. The statistics show that the number of respiratory patients increases by $60 \%$ on the days when Tehran air pollution is high. The most important factor associated with exacerbation of cardiovascular and pulmonary diseases is the increase of pollutants $\mathrm{O}_{3}$, 
$\mathrm{CO}$ and suspended particulate matters. Air pollution in Tehran, on average, leads to a 5-year reduction in the life expectancy of the people of Tehran. Here, we evaluated the air pollution in Tehran for three consecutive days in November 2017, and the data were obtained from five air-quality monitoring stations located in different parts of the city. These stations measure the suspended particulate matters $\mathrm{PM}_{2.5}, \mathrm{PM}_{10}$ and pollutants $\mathrm{O}_{3}, \mathrm{CO}$. We considered the stations as DMs $(t=5)$, three consecutive days as alternatives $(m=3)$, and suspended particulate matters and pollutants as criteria $(n=4)$. The information obtained from five air-quality monitoring stations located in different parts of the city for three consecutive days is shown in Tables 6-10.

In Step 1, since all criteria are of cost type, normalize the matrices using Eq. (7). The weights of $\mathrm{PM}_{2.5}, \mathrm{PM}_{10}, \mathrm{O}_{3}$, and $\mathrm{CO}$ are considered as $0.3,0.3$,

Table 6. Data related to Aqdasieh station $\left(X_{1}\right)$.

\begin{tabular}{ccccc}
\hline Alternative & $\mathbf{P M}_{\mathbf{2 . 5}}$ & $\mathbf{P M}_{\mathbf{1 0}}$ & $\mathbf{O}_{\mathbf{3}}$ & $\mathbf{C O}$ \\
\hline$A_{1}$ & {$[95,104]$} & {$[47,50]$} & {$[71,73]$} & {$[19,28]$} \\
$A_{2}$ & {$[94,96]$} & {$[53,54]$} & {$[93,99]$} & {$[22,29]$} \\
$A_{3}$ & {$[71,72]$} & {$[56,57]$} & {$[90,91]$} & {$[30,31]$} \\
\hline
\end{tabular}

Table 7. Data related to Rose Park station $\left(X_{2}\right)$.

\begin{tabular}{ccccc}
\hline Alternative & $\mathbf{P M}_{\mathbf{2 . 5}}$ & $\mathbf{P M}_{\mathbf{1 0}}$ & $\mathbf{O}_{\mathbf{3}}$ & $\mathbf{C O}$ \\
\hline$A_{1}$ & {$[71,74]$} & {$[58,59]$} & {$[37,38]$} & {$[13,26]$} \\
$A_{2}$ & {$[62,63]$} & {$[59,60]$} & {$[37,40]$} & {$[21,29]$} \\
$A_{3}$ & {$[67,78]$} & {$[63,64]$} & {$[54,55]$} & {$[26,28]$} \\
\hline
\end{tabular}

Table 8. Data related to Pounak station $\left(X_{3}\right)$.

\begin{tabular}{ccccc}
\hline Alternative & $\mathbf{P M}_{\mathbf{2 . 5}}$ & $\mathbf{P M}_{\mathbf{1 0}}$ & $\mathbf{O}_{\mathbf{3}}$ & $\mathbf{C O}$ \\
\hline$A_{1}$ & {$[85,86]$} & {$[60,63]$} & {$[72,73]$} & {$[18,20]$} \\
$A_{2}$ & {$[82,83]$} & {$[60,62]$} & {$[69,70]$} & {$[30,31]$} \\
$A_{3}$ & {$[82,83]$} & {$[66,68]$} & {$[72,73]$} & {$[36,39]$} \\
\hline
\end{tabular}

Table 9. Data related to Pirouzi station $\left(X_{4}\right)$.

\begin{tabular}{ccccc}
\hline Alternative & $\mathbf{P M}_{\mathbf{2 . 5}}$ & $\mathbf{P M}_{\mathbf{1 0}}$ & $\mathbf{O}_{\mathbf{3}}$ & $\mathbf{C O}$ \\
\hline$A_{1}$ & {$[83,84]$} & {$[71,72]$} & {$[55,57]$} & {$[22,37]$} \\
$A_{2}$ & {$[92,96]$} & {$[77,79]$} & {$[62,66]$} & {$[29,30]$} \\
$A_{3}$ & {$[92,95]$} & {$[81,83]$} & {$[80,81]$} & {$[25,28]$} \\
\hline
\end{tabular}

Table 10. Data related to Tarbiat Modarres station $\left(X_{5}\right)$.

\begin{tabular}{ccccc}
\hline Alternative & $\mathbf{P M}_{\mathbf{2 . 5}}$ & $\mathbf{P M}_{\mathbf{1 0}}$ & $\mathbf{O}_{\mathbf{3}}$ & $\mathbf{C O}$ \\
\hline$A_{1}$ & {$[74,77]$} & {$[60,61]$} & {$[73,74]$} & {$[31,38]$} \\
$A_{2}$ & {$[85,87]$} & {$[69,70]$} & {$[98,99]$} & {$[32,46]$} \\
$A_{3}$ & {$[90,92]$} & {$[78,79]$} & {$[99,100]$} & {$[21,36]$} \\
\hline
\end{tabular}

0.2 , and 0.2, respectively. In Step 2, weigh the matrices by considering the mentioned weights (Tables 11-15).

In Step 3, determine the PIS $\left(A^{+}\right)$and NIS $\left(A^{-}\right)$ by Eqs. (9) and (10), respectively (Tables 16 and 17). In Step 4, apply Eqs. (11) and (12) to calculate $s_{k}^{+}$and $s_{k}^{-}$values, respectively, which are shown in Table 18 . In Step 5, calculate $R C_{k}$ values by Eq. (13) (Table 18); in this step, rank all DMs in descending order by these values. In Step 6, apply Eq. (14) to determine $\lambda_{k}$ values (Table 18). In Step 7, utilize Eq. (15) to weigh the decision matrices. In Step 8, construct matrix $V$ by Eq. (16), as shown in Table 19 .

In Step 9, calculate interval values $V_{i}(i=1,2,3)$ as follows:

$$
\begin{aligned}
& V_{1}=[0.73593,1.14716], \\
& V_{2}=[0.68847,1.03565], \\
& V_{3}=[0.66080,0.99443] .
\end{aligned}
$$

In Step 10, obtain the complimentary matrix $P$ as follows:

$$
P=\left[\begin{array}{ccc}
0.5 & 0.60480 & 0.65295 \\
0.39520 & 0.5 & 0.55059 \\
0.34705 & 0.44941 & 0.5
\end{array}\right]
$$

In Step 11, by summing up all components of each row of matrix $P$, we have $P_{1}=1.75776, P_{2}=1.44579$, and $P_{3}=1.29645$. Then, alternatives are ranked based on $P_{i}(i=1,2,3)$ values in descending order. Since $P_{1}>P_{2}>P_{3}$, so we have $A_{1} \succ A_{2} \succ A_{3}$. This means that the best alternative is $A_{1}$, hence the first day has the best air quality.

As seen in Table 18, $s_{k}^{+}$(the distance of decision of the $k$ th DM from the PIS) and $s_{k}^{-}$(the distance of decision of the $k$ th DM from the NIS) could be employed to rank DMs. The smaller the $s_{k}^{+}$value, the better the decision of the $k$ th $\mathrm{DM}$; in addition, the larger the $s_{k}^{-}$value, the better the decision of the $k$ th DM. Table 18 shows that in ranking DMs based on "farther away from the NIS is better", the fourth DM is ranked the last, while the decision of this DM is closest to the PIS. However, in the ranking based on $R C_{k}$ values, being closer to the PIS and farther away from the NIS is considered simultaneously, and a DM whose decision is closer to the PIS and farther away from the NIS will be assigned a higher weight and a DM whose decision is farther away from the PIS and closer to the NIS will be assigned lower weight, because the opinions of DMs are either biased (directed) or false.

\section{Conclusions}

In this study, the interval numbers that include uncertainly in the decision-making process were employed. 
Table 11. Weighted normalized data related to Aqdasieh station ( $\left.V_{1}\right)$.

\begin{tabular}{ccccc}
\hline Alternative & $\mathbf{P M}_{\mathbf{2 . 5}}$ & $\mathbf{P M}_{\mathbf{1 0}}$ & $\mathbf{O}_{\mathbf{3}}$ & $\mathbf{C O}$ \\
\hline$A_{1}$ & {$[0.20481,0.22421]$} & {$[0.28200,0.30000]$} & {$[0.19452,0.20000]$} & {$[0.13571,0.20000]$} \\
$A_{2}$ & {$[0.22188,0.22660]$} & {$[0.26111,0.26604]$} & {$[0.14343,0.15269]$} & {$[0.13103,0.17273]$} \\
$A_{3}$ & {$[0.29583,0.30000]$} & {$[0.24737,0.25179]$} & {$[0.15604,0.15778]$} & {$[0.12258,0.12667]$} \\
\hline
\end{tabular}

Table 12. Weighted normalized data related to Rose Park station $\left(V_{2}\right)$.

\begin{tabular}{ccccc}
\hline Alternative & $\mathbf{P M}_{\mathbf{2 . 5}}$ & $\mathbf{P M}_{\mathbf{1 0}}$ & $\mathbf{O}_{\mathbf{3}}$ & $\mathbf{C O}$ \\
\hline$A_{1}$ & {$[0.25135,0.26197]$} & {$[0.29492,0.30000]$} & {$[0.19474,0.20000]$} & {$[0.10000,0.20000]$} \\
$A_{2}$ & {$[0.29524,0.30000]$} & {$[0.29000,0.29492]$} & {$[0.18500,0.20000]$} & {$[0.08966,0.12381]$} \\
$A_{3}$ & {$[0.23846,0.27761]$} & {$[0.27188,0.27619]$} & {$[0.13455,0.13704]$} & {$[0.09286,0.10000]$} \\
\hline
\end{tabular}

Table 13. Weighted normalized data related to Pounak station $\left(V_{3}\right)$.

\begin{tabular}{ccccc}
\hline Alternative & $\mathbf{P M}_{\mathbf{2 . 5}}$ & $\mathbf{P M}_{\mathbf{1 0}}$ & $\mathbf{O}_{\mathbf{3}}$ & $\mathbf{C O}$ \\
\hline$A_{1}$ & {$[0.28605,0.28941]$} & {$[0.28571,0.30000]$} & {$[0.18904,0.19167]$} & {$[0.18000,0.20000]$} \\
$A_{2}$ & {$[0.29639,0.30000]$} & {$[0.29032,0.30000]$} & {$[0.19714,0.20000]$} & {$[0.11613,0.12000]$} \\
$A_{3}$ & {$[0.29639,0.30000]$} & {$[0.26471,0.27273]$} & {$[0.18904,0.19167]$} & {$[0.09231,0.10000]$} \\
\hline
\end{tabular}

Table 14. Weighted normalized data related to Pirouzi station $\left(V_{4}\right)$.

\begin{tabular}{ccccc}
\hline Alternative & $\mathbf{P M}_{\mathbf{2 . 5}}$ & $\mathbf{P M}_{\mathbf{1 0}}$ & $\mathbf{O}_{\mathbf{3}}$ & $\mathbf{C O}$ \\
\hline$A_{1}$ & {$[0.29643,0.30000]$} & {$[0.29583,0.30000]$} & {$[0.19298,0.20000]$} & {$[0.11892,0.20000]$} \\
$A_{2}$ & {$[0.25938,0.27065]$} & {$[0.26962,0.27662]$} & {$[0.16667,0.17742]$} & {$[0.14667,0.15172]$} \\
$A_{3}$ & {$[0.26211,0.27065]$} & {$[0.25663,0.26296]$} & {$[0.13580,0.13750]$} & {$[0.15714,0.17600]$} \\
\hline
\end{tabular}

Table 15. Weighted normalized data related to Tarbiat Modarres station $\left(V_{5}\right)$.

\begin{tabular}{ccccc}
\hline Alternative & $\mathbf{P M}_{\mathbf{2 . 5}}$ & $\mathbf{P M}_{\mathbf{1 0}}$ & $\mathbf{O}_{\mathbf{3}}$ & $\mathbf{C O}$ \\
\hline$A_{1}$ & {$[0.28831,0.30000]$} & {$[0.29508,0.30000]$} & {$[0.19730,0.20000]$} & {$[0.11053,0.13548]$} \\
$A_{2}$ & {$[0.25517,0.26118]$} & {$[0.25714,0.26087]$} & {$[0.14747,0.14898]$} & {$[0.09130,0.13125]$} \\
$A_{3}$ & {$[0.24130,0.24667]$} & {$[0.22785,0.23077]$} & {$[0.14600,0.14747]$} & {$[0.11667,0.20000]$} \\
\hline
\end{tabular}

Table 16. Positive ideal solution $\left(A^{+}\right)$.

\begin{tabular}{ccccc}
\hline Alternative & $\mathbf{P M}_{\mathbf{2 . 5}}$ & $\mathbf{P M}_{\mathbf{1 0}}$ & $\mathbf{O}_{\mathbf{3}}$ & $\mathbf{C O}$ \\
\hline$A_{1}$ & {$[0.26539,0.27512]$} & {$[0.29071,0.30000]$} & {$[0.19372,0.19833]$} & {$[0.12903,0.18710]$} \\
$A_{2}$ & {$[0.26561,0.27168]$} & {$[0.27364,0.27969]$} & {$[0.16794,0.17582]$} & {$[0.11496,0.13990]$} \\
$A_{3}$ & {$[0.26682,0.27899]$} & {$[0.25368,0.25889]$} & {$[0.15229,0.15429]$} & {$[0.11631,0.14053]$} \\
\hline
\end{tabular}

Table 17. Negative ideal solution $\left(A^{-}\right)$.

\begin{tabular}{ccccc}
\hline Alternative & $\mathbf{P M}_{\mathbf{2 . 5}}$ & $\mathbf{P M}_{\mathbf{1 0}}$ & $\mathbf{O}_{\mathbf{3}}$ & $\mathbf{C O}$ \\
\hline$A_{1}$ & {$[0.20481,0.30000]$} & {$[0.28200,0.30000]$} & {$[0.18904,0.20000]$} & {$[0.10000,0.20000]$} \\
$A_{2}$ & {$[0.22188,0.30000]$} & {$[0.25714,0.30000]$} & {$[0.14343,0.20000]$} & {$[0.08966,0.17273]$} \\
$A_{3}$ & {$[0.23846,0.30000]$} & {$[0.22785,0.27619]$} & {$[0.13455,0.19167]$} & {$[0.09231,0.20000]$} \\
\hline
\end{tabular}

Table 18. Decision Makings (DMs) ranking.

\begin{tabular}{ccccccc}
\hline Parameter & $\boldsymbol{d}_{\mathbf{1}}$ & $\boldsymbol{d}_{\mathbf{2}}$ & $\boldsymbol{d}_{\mathbf{3}}$ & $\boldsymbol{d}_{\mathbf{4}}$ & $\boldsymbol{d}_{5}$ & $\mathbf{R}$ \\
\hline$S_{k}^{+}$ & {$[0.06163,0.13835]$} & {$[0.03774,0.13519]$} & {$[0.05578,0.12130]$} & {$[0.03153,0.11104]$} & {$[0.04087,0.14349]$} & $d_{4} \succ d_{2} \succ d_{3} \succ d_{5} \succ d_{1}$ \\
$S_{k}^{-}$ & {$[0.00000,0.22159]$} & {$[0.00000,0.22849]$} & {$[0.00000,0.22936]$} & {$[0.00000,0.20152]$} & {$[0.00000,0.22408]$} & $d_{3} \succ d_{2} \succ d_{5} \succ d_{1} \succ d_{4}$ \\
$R C_{k}$ & {$[0.45872,0.54697]$} & {$[0.45833,0.55192]$} & {$[0.45970,0.54967]$} & {$[0.46376,0.54607]$} & {$[0.45792,0.55040]$} & $d_{2} \succ d_{4} \succ d_{3} \succ d_{5} \succ d_{1}$ \\
$\lambda_{k}$ & {$[0.16711,0.23798]$} & {$[0.16697,0.24013]$} & {$[0.16747,0.23915]$} & {$[0.16895,0.23759]$} & {$[0.16682,0.23947]$} & $d_{2} \succ d_{4} \succ d_{3} \succ d_{5} \succ d_{1}$ \\
\hline
\end{tabular}


Table 19. Collective decision matrix $(V)$.

\begin{tabular}{ccccc}
\hline Alternative & $\mathbf{P M}_{\mathbf{2 . 5}}$ & $\mathbf{P M}_{\mathbf{1 0}}$ & $\mathbf{O}_{\mathbf{3}}$ & $\mathbf{C O}$ \\
\hline$A_{1}$ & {$[0.22227,0.32859]$} & {$[0.24342,0.35829]$} & {$[0.16220,0.23687]$} & {$[0.10805,0.22341]$} \\
$A_{2}$ & {$[0.22239,0.32455]$} & {$[0.22912,0.33406]$} & {$[0.14063,0.21002]$} & {$[0.09632,0.16701]$} \\
$A_{3}$ & {$[0.22342,0.33317]$} & {$[0.21243,0.30920]$} & {$[0.12750,0.18427]$} & {$[0.09746,0.16778]$} \\
\hline
\end{tabular}

Motivated by the abilities of interval numbers, this paper presented a new approach to solving Group Multiple Criteria Decision Making (GMCDM) problems in the presence of interval data. Here, an interval-based approach to weighing the Decision Makings (DMs) and ranking the alternatives was proposed. The proposed model provided more reasonable results since it produced interval weights that were consistent with given data. Two illustrative examples were presented to show the applicability of the proposed procedure. As is clear, Multiple Criteria Decision Making (MCDM) methods use various calculation schemes to evaluate the rank of alternatives. However, little evidence supports the consistency between the alternative chosen by the MCDM method and the decision-maker's intuitive ideal alternative. Therefore, the extension of an operational validation scheme to examining and comparing the effectiveness of interval MCDM methods is proposed for future research. Another topic is investigating the effect of weights on the interval MCDM methods. Moreover, method-oriented parameter settings such as normalization method and distance function can be examined. Besides, a supplementary approach can be developed for situations in which the information is expressed as fuzzy or interval fuzzy numbers.

\section{Acknowledgement}

The authors would like to thank the Editor in Chief and three anonymous reviewers for their helpful comments and suggestions.

\section{References}

1. Ishizaka, A. and Nemery P., Multi-Criteria Decision Analysis: Methods and Software, John Wiley and Sons (2013).

2. Keeney, R. and Raiffa, H., Decisions With Multiple Objectives: Preferences and Value Tradeoffs, New York: Wiley (1976).

3. Köksalan, M., Wallenius, J., and Zoints, S., Multiple Criteria Decision Making: From Early History to the 21st Century, World Scientific Publishing, New Jersey (2011).

4. Jacquet-Lagréze, E. and Siskos, J. "Assessing a set of additive utility functions for multiple criteria decision making", European Journal of Operational Research, 10, pp. 151-164 (1982).
5. Solymosi, T. and Dombi, J. "A method for determining the weights of criteria: the centralized weights", European Journal of Operational Research, 26, pp. 35-41 (1986).

6. Guitouni, A. and Martel, J.M. "Tentative guidelines to help choosing an appropriate MCDA method", European Journal of Operational Research, 109, pp. 501-521 (1998).

7. Figueira, J., Salvatore, G., and Ehrgott, M., Eds, Multiple Criteria Decision Analysis: State of the Art Surveys, New York: Springer Science \& Business Media (2005).

8. Wallenius, J., Dyer, J.S., Fishburn, P.C., Steuer, R.E., Zionts, S., and Deb, K. "Multiple criteria decision making, multiattribute utility theory: recent accomplishments and what lies ahead", Management Science, 54, pp. 1336-1349 (2008).

9. Hwang, C.L. and Yoon, K., Multiple Attributes Decision Making Methods and Applications, Berlin, Heidelberg: Springer (1981).

10. Opricovic, S. and Tzeng, G.-H. "Compromise solution by MCDM methods", European Journal of Operational Research, 156(2), pp. 445-455 (2004).

11. Saaty, T.L., "A scaling method for priorities in hierarchical structures", Journal of Mathematical Psychology, 15, pp. 234-281 (1977).

12. Edwards, W. "How to use multi attribute utility measurement for social decision making", IEEE Transactions on Systems, Man and Cybernetics, 7, pp. 326340 (1977).

13. Banae Costa, C. and Vansnick, J.-C. "MACBETH - An interactive path towards the construction of cardinal value functions", International Transactions in Operational Research, 1, pp. 489-500 (1994).

14. Govindan, K. and Jespen, MB. "ELECTRE: A comprehensive literature review on methodologies and applications", European Journal of Operational Research, 250, pp. 1-29 (2016).

15. Ishizaka, A. and Siraj, S. "Are multi-criteria decisionmaking tools useful? An experimental comparative study of three methods", European Journal of Operational Research, 264(2), pp. 462-471 (2017).

16. Nassereddine, M. and Eskandari, H. "An integrated MCDM approach to evaluate public transportation systems in Tehran", Transportation Research Part A: Policy and Practice, 106, pp. 427-439 (2017).

17. Abdollahi, A., Pour-Moallem, N., and Abdollahi, A. "Dynamic negawatt demand response resource modeling and prioritizing in power markets", Scientia Iranica, 27(3), pp. 1361-1372 (2020). 
18. Gou, X., Xu, Z., and Liao, H. "Hesitant fuzzy linguistic entropy and cross-entropy measures and alternative queuing method for multiple criteria decision making", Information Sciences, 388, pp. 225-246 (2017).

19. Ren, Z., Xu, Z., and Wang, H. "Dual hesitant fuzzy VIKOR method for multi-criteria group decision making based on fuzzy measure and new comparison method", Information Sciences, 388, pp. 1-16 (2017).

20. Zavadskas, E.K., Antucheviciene, J., Turskis, Z., and Adeli, H. "Hybrid multiple-criteria decision-making methods: A review of applications in engineering", Scientia Iranica., Transactions A, Civil Engineering, 23(1), p. 1 (2016).

21. Chen, L. and $\mathrm{Xu}, \mathrm{Z}$. "A new prioritized multi-criteria outranking method: The prioritized PROMETHEE", Journal of Intelligent \& Fuzzy Systems, 29(5), pp. 2099-2110 (2015).

22. Yu, X., Xu, Z., and Ma, Y. "Prioritized multi-criteria decision making based on the idea of PROMETHEE", Procedia Computer Science, 17, pp. 449-456 (2013).

23. Keeney, R.L. and Kirkwood, C.W. "Group decision making using cardinal social welfare functions", Management Science, 22, pp. 430-437 (1975).

24. Keeney, R.L. "A group preference axiomatization with cardinal utility", Management Science, 23, pp. 140145 (1976).

25. Brock, H.W. "The problem of 'utility weights' in group preference aggregation", Operations Research, 28, pp. 176-187 (1980).

26. Ramanathan, R. and Ganesh, L.S. "Group preference aggregation methods employed in AHP: an evaluation and an intrinsic process for deriving members' weightages", European Journal of Operational Research, 79, pp. 249-265 (1994).

27. Van den Honert, R.C. "Decisional power in group decision making: a note on the allocation of group members weights in the multiplicative AHP and SMART", Group Decision and Negotiation, 10, pp. 275-286 (2001).

28. Xu, Z.S. "Group decision making based on multiple types of linguistic preference relations", Information Sciences, 178, pp. 452-467 (2008).

29. Abootalebi, S., Hadi-Vencheh, A., and Jamshidi, A. "An Improvement to determining expert weights in group multiple attribute decision making problem", Group Decision and Negotiation, 27(2), pp. 215-221 (2018).

30. Wang, H.-F., Multicriteria Decision Analysis - From Certainty to Uncertainty, Ting Lung Book Co, Taipei (2004).

31. Mahmoudi, A., Sadi-Nezhad, S., and Makui, A. "An extended fuzzy VIKOR for group decisionmaking based on fuzzy distance to supplier selection", Scientia Iranica., Transactions E, Industrial Engineer- ing, 23(4), p. 1879 (2016).

32. Hu, J., Chen, P., and Chen, X. "Intuitionistic random multi-criteria decision-making approach based on prospect theory with multiple reference intervals", Scientia Iranica., Transactions E, Industrial Engineering, 21(6), p. 2347 (2014)

33. Minatour, Y., Khazaie, J., Ataei, M., and Javadi, A.A. "An integrated decision support system for dam site selection", Scientia Iranica., Transactions A, Civil Engineering, 22(2), p. 319 (2015).

34. Yu, X., Zhang, S., Liao, X., and Qi, X. "ELECTRE methods in prioritized MCDM environment", Information Sciences, 424, pp. 301-316 (2018).

35. Yue, Z. "An extended TOPSIS for determining weights of decision makers with interval numbers", KnowledgeBased Systems, 24, pp. 146-153 (2011).

36. Jahanshahloo, G.R., Hosseinzadeh Lotfi, F., and Izadikhah, M. "An algorithmic method to extend TOPSIS for decision-making problems with interval data", Applied Mathematics and Computation, 175, pp. 1375-1384 (2006).

37. Sayadi, M.K., Heydari, M., and Shahanaghi, K. "Extension of VIKOR method for decision making problem with interval numbers", Applied Mathematical Modelling, 33, pp. 2257-2262 (2009).

38. Rezaei, J. and Salimi, N. "Optimal ABC inventory classification using interval Programming", International Journal of Systems Science, 46(11), pp. 19441952 (2015).

39. Dymova, L., Sevastjanov, P., and Tikhonenko, A. "A direct interval extension of TOPSIS method", Expert Systems with Applications, 40, pp. 4841-4847 (2013).

40. Hafezalkotob, A., Hafezalkotob, A., and Sayadi, M.K. "Extension of MULTIMOORA method with interval numbers: An application in materials selection", Applied Mathematical Modelling, 40, pp. 1372-1386 (2016).

41. Liu, W. and Li, L. "An approach to determining the integrated weights of decision makers based on interval number group decision matrices", Knowledge-Based Systems, 90, pp. 92-98 (2015).

42. Pamučar, D., Stević, Z̆., and Zavadskas, E.K. "Integration of interval rough AHP and interval rough MABAC methods for evaluating university web pages", Applied Soft Computing, 67, pp. 141-163 (2018).

43. Feng, Y., Hong, Z., Tian, G., Li, Z., Tan, J., and Hu, H. "Environmentally friendly MCDM of reliabilitybased product optimisation combining DEMATELbased ANP, interval uncertainty and Vlse Kriterijumska Optimizacija Kompromisno Resenje (VIKOR)", Information Sciences, 442, pp. 128-144 (2018).

44. Wanke, P., Kalam Azad, M.A., Barros, C.P., and Hadi-Vencheh, A. "Predicting performance in ASEAN banks: an integrated fuzzy MCDM-neural network approach", Expert Systems, 33(3), pp. 213-229 (2016). 
45. Hajek, P. and Froelich, W. "Integrating TOPSIS with interval-valued intuitionistic fuzzy cognitive maps for effective group decision making", Information Sciences, 485, pp. 394-412 (2019).

46. Frini, A. and Amor, S.B. "MUPOM: A multi-criteria multi-period outranking method for decision-making in sustainable development context", Environmental Impact Assessment Review, 76, pp. 10-25 (2019).

47. Alefeld, G. and Herzberger, J., Introduction to Interval Computations, New York: Academic Press (1983).

48. Xu, Z.S. "On method for uncertain multiple attribute decision making problems with uncertain multiplicative preference information on alternatives", Fuzzy Optimization and Decision Making, 4, pp. 131-139 (2005).

49. Xu, Z.S. "Dependent uncertain ordered weighted aggregation operators", Information Fusion, 9, pp. 310316 (2008).

50. Li, D.-F. "Relative ratio method for multiple attribute decision making problems", International Journal of Information Technology \& Decision Making, 8(2) pp. 289-311 (2009).

\section{Biographies}

Saghi Saffarzadeh is a PhD Candidate at Islamic Azad University (IAU), Isfahan Branch, Iran. Her fields of study are multiple criteria decision making, interval programming, fuzzy mathematical programming, and data envelopment analysis. She has published some papers in international journals and at the moment, she is working on her $\mathrm{PhD}$ thesis.

Abdollah Hadi-Vencheh is a Full Professor of Operations Research and Decision Sciences at IAU, Isfahan Branch, Iran. His research interests lie in the broad area of multiple criteria decision making, performance management, data envelopment analysis, fuzzy mathematical programming, and fuzzy decision making. He has published more than 100 papers in more prestigious international journals such as European Journal of Operational Research, IEE Transaction on Fuzzy Systems, Information Sciences, Computers and Industrial Engineering, Journal of the Operational Research Society, Journal of manufacturing systems, Expert Systems with Applications, Expert Systems, Measurement, Kybernetes, Optimization, Optimization Letters, Scientia Iranica, Computers in Industry, and International Journal of Computer Integrated Manufacturing.

Ali Jamshidi is an Assistant Professor of Operations Research. His research interests include multiple criteria decision modeling, data envelopment analysis, supply chain management, and scheduling. He has published several papers in international journals. 